\title{
cepead
}

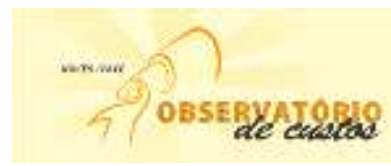

\section{AÇÕES E ESTRATÉGIAS SUSTENTÁVEIS EM UMA EMPRESA DE COLETA DE RESÍDUOS DE SERVIÇOS DE SAÚDE.}

\section{SUSTAINABLE ACTIONS AND STRATEGIES IN A WASTE COLLECTION COMPANY OF HEALTH SERVICES.}

\section{ACCIONES Y ESTRATÉGIAS SOSTENIBLES EN UNA EMPRESA DE RECOGIDA DE RESÍDUOS DE SERVICIOS DE SALUD.}

Vanessa Almeida da Silva

Universidade Federal de Santa Maria

va.almeida@hotmail.com

Laércio André Gassen Balsan

Universidade Federal de Santa Maria

laerciobalsan@yahoo.com.br

Thiago Beuron

Universidade Federal de Santa Maria

tbeuron@gmail.com

Lisiane Pellini Faller

Universidade Federal de Santa Maria

lisifaller@gmail.com

Lucia Rejane da Rosa Gama Madruga

Universidade Federal de Santa Maria

luciagm@ufsm.br
Submetido em: 05/04/2014

Artigo aceito em: 04/05/2015

\section{Resumo}

O presente estudo analisa uma organização responsável pela coleta, transporte, tratamento e destinação final de resíduos especiais. Seu objetivo foi analisar as ações e estratégias sustentáveis da empresa relacionados aos resíduos de serviços de saúde, de modo a caracterizar as especificidades da organização, bem como descrever a gestão dos resíduos. Este estudo de caso envolveu opiniões e percepções dos gestores de uma filial da empresa quanto às ações e estratégias sustentáveis adotadas. Devido a sua atuação na área de resíduos especiais, a empresa possui características próprias que lhe conferem especificidades. A conclusão do estudo demonstrou que existe uma percepção por parte dos gestores quanto aos objetivos econômicos, sociais e ambientais definidos pela organização, onde a adoção de práticas ambientais deve refletir a responsabilidade social da empresa, enfatizando a importância de gerar uma imagem legitimada e institucionalizada na sociedade.

Palavras-chave: Ações sustentáveis; Resíduos de serviços de saúde; Políticas ambientais.

\section{Abstract}

This study analyzes an organization responsible for collection, transportation, treatment and disposal of special waste. The goal was to analyze the actions and sustainable business strategies related to waste health services, in order to characterize the specifics of the organization and to describe the management of waste . This case study involved the opinions and perceptions of managers of a subsidiary enterprise of sustainable actions and strategies adopted. Due to its performance in the area of special waste, the company has its own characteristics that give specifics. The conclusion of the study showed that there is a perception by managers about the economic, social and environmental objectives set by the organization, where the adoption of environmental practices should reflect the company's social responsibility, emphasizing the importance of generating a legitimized and institutionalized in the image society.

Keywords : Sustainable actions ; Waste from health services ; Environmental policies. 

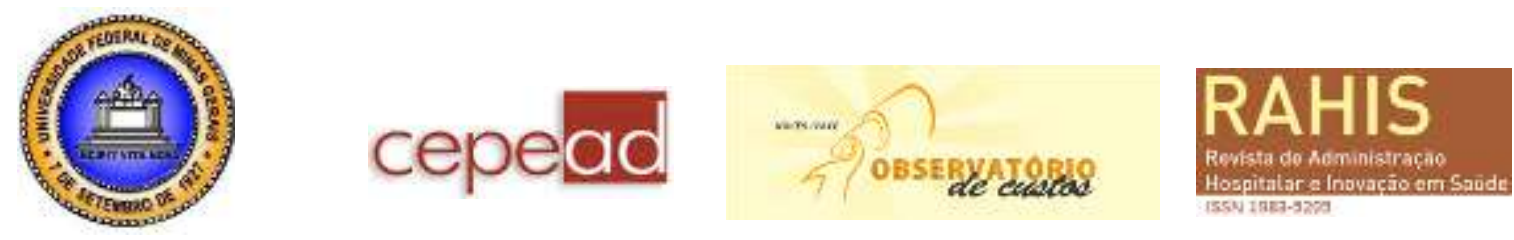

\section{Resumen}

Este estudio analiza una organización responsable de la recolección, transporte, tratamiento y disposición de la organización de residuos especiales. Su objetivo fue analizar las acciones y estrategias de negocio sostenibles relacionados con los residuos de servicios de salud, con el fin de caracterizar los detalles de la organización y para describir la gestión de los residuos. Este estudio de caso involucró las opiniones y percepciones de los directivos de una empresa filial de acciones sostenibles y estrategias adoptadas. Debido a su desempeño en el área de residuos especiales, la compañía tiene sus propias características que dan más detalles. La conclusión del estudio mostró que existe una percepción de los gerentes acerca de los objetivos económicos, sociales y médio ambientales fijados por la organización, donde la adopción de prácticas ambientales debe reflejar la responsabilidad social de la empresa, haciendo hincapié en la importancia de generar una legitimado e institucionalizado en la imagen la sociedad.

Palabras clave: Acciones sostenibles; Residuos de los servicios de salud; Las políticas ambientales.

\section{Introdução}

Dentre as questões ambientais mais preocupantes e discutidas na atualidade estão os resíduos (ALVES, 2008), principalmente devido ao comportamento consumista da sociedade atual (ALVES, 2008; MORESCHI, 2013).

A partir da segunda metade do século XX houve um aumento sucessivo na produção de resíduos, ultrapassando a capacidade de absorção da natureza (MORESCHI, 2013). A crescente quantidade de resíduos produzida diariamente em todo o território nacional, aliada ao fato de a maioria dos municípios brasileiros não contar com estruturação física adequada para tratamento e cuidado com os resíduos e também para a recepção e/ou separação de rejeitos sólidos, torna a discussão acerca deste tema imprescindível, uma vez que se trata de um problema que pode afetar diretamente a saúde pública (RODRIGUES; BASTOS; MALAFAIA, 2010). Joshi (2013) afirma que a gestão de resíduos de saúde tornou-se uma necessidade urgente para salvaguardar a saúde pública dos efeitos adversos causados pelo manejo inadequado desse tipo de resíduo. Por esses motivos, a gestão de resíduos de serviços da saúde continua a apresentar uma série de desafios para os países em desenvolvimento (JOSHI, 2013).

O movimento do desenvolvimento sustentável fundamenta-se na percepção de que ultrapassar a capacidade de carga do planeta implica em catástrofes sociais e ambientais e são vários os indícios de que os limites admissíveis já foram ultrapassados (BARBIERI; CAJAZEIRA, 2009).

Cabe destacar que é recente a aprovação da Política Nacional de Resíduos Sólidos (PNRS), instituída pela Lei $\mathrm{n}^{\circ} 12.305 / 10$. Essa lei mostra avanços na responsabilização de todos os agentes em todas as esferas da sociedade no que tange aos problemas sociais, ambientais e econômicos gerados pelos resíduos, e também com a prevenção, a redução e a busca por padrões mais sustentáveis, incluindo até mesmo a logística reversa, como responsabilidade de todos os agentes envolvidos no processo de produção (BRASIL, 2012).

Ao tratar desse assunto adota-se a definição de resíduos proposta pela NBR 12807 da ABNT (1993) que define Resíduos de Serviços de Saúde (RSS) como aqueles resultantes das atividades exercidas por estabelecimentos prestadores de serviços de saúde. Coelho (2001) acrescenta que os RSS são aqueles gerados por prestadores de assistência médica, odontológica, laboratorial, farmacêutica e ainda instituições de pesquisa e ensino de cunho humano ou veterinário. Esses resíduos exigem cuidados especiais justamente pelos riscos de contaminação que geram, entre os quais, biológicos, químicos e radioativos. Assim, os cuidados são redobrados e específicos com o acondicionamento, transporte, armazenamento, coleta, tratamento e disposição final desses materiais. Tais cuidados são potencializados pela 

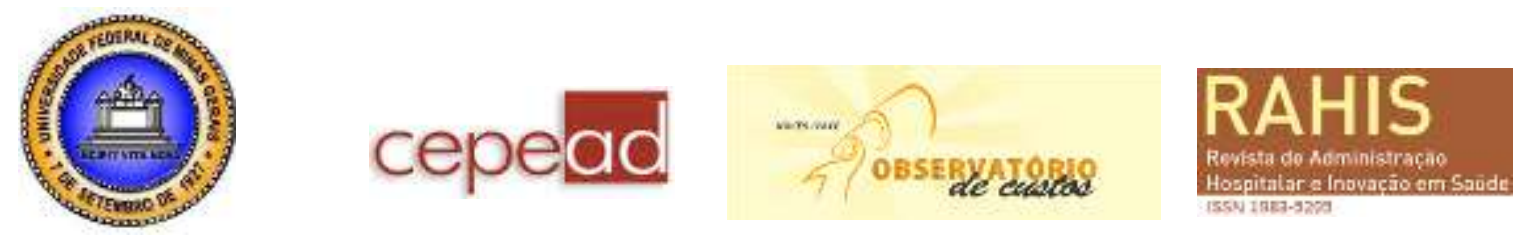

preocupação com a prevenção de possíveis impactos que possam refletir na população e no meio ambiente (CARRAMENHA, 2005).

Tendo em vista a importância dos RSS para a manutenção da saúde pública e ambiental e considerando que, segundo Alves (2008), a partir de julho de 2005, por força da Lei $n^{0}$ 358/2005 do CONAMA, a maioria dos estabelecimentos hospitalares está enviando seus RSS para serem tratados fora dos estabelecimentos por meio de empresas terceirizadas, surgiu o interesse em se ampliar a compreensão acerca das ações e estratégias sustentáveis em uma empresa de coleta de resíduos dessa natureza.

Nesse contexto, o estudo tem como objetivos: (i) caracterizar as especificidades da coleta de resíduos de serviços de saúde; (ii) descrever a gestão dos resíduos por parte da empresa objeto de estudo; e (iii) analisar as estratégias e ações sustentáveis realizadas pela organização.

Este estudo ganha relevância à medida que, segundo Alves (2008), o gerenciamento dos resíduos nos estabelecimentos de saúde é uma realidade ainda pouco explorada no Brasil.

O texto está organizado em seis seções, iniciando pela introdução. Na sequência, a segunda e terceira seções abordam o quadro teórico que serviu de referência à construção do conhecimento. A quarta seção especifica os procedimentos metodológicos adotados para a realização do trabalho. A quinta parte apresenta e analisa os principais achados da pesquisa. $\mathrm{E}$ por fim, são destacadas as considerações finais acerca do estudo e apresentadas as referências utilizadas.

\section{Sustentabilidade Organizacional}

Neste estudo, adota-se a perspectiva do capitalismo natural, uma visão sistêmica e não linear, na qual os sistemas vivos são autoprodutores e a sustentabilidade das partes só pode ocorrer de fato quando houver a sustentabilidade do todo no qual elas estão inseridas, ou seja, trata-se de um modelo em que todos participam dos ganhos (HAWKEN et al., 2000). Como parte do modelo apontam algumas medidas a serem absorvidas como forma de preservar o capital natural e gerar benefícios a toda comunidade:

- Redução no uso de recursos: os recursos devem ser utilizados de forma mais efetiva, possibilitando a reutilização dos mesmos e direcionando atenção ao descarte do produto;

- Biomimetismo: os autores sugerem soluções "lean and clean", ou seja, "limpas e sem excesso", com nada de desperdício; as empresas e os indivíduos deveriam se espelhar nos ciclos da natureza (fechados e contínuos), repensar na forma em que os resíduos retornam à natureza e utilizar práticas de reciclagem;

- Mudança nos padrões de consumo: ênfase nos serviços e não mais nos produtos - ao invés de adquirir determinado bem o indivíduo o alugaria;

- Investimento no capital natural: oferecer a devida atenção às práticas sustentáveis para preservar as fontes renováveis do capital natural.

Essas medidas fazem parte do conjunto das expectativas depositadas nas empresas, que além de garantir rentabilidade, devem focar em objetivos sociais, ambientais e econômicos (MATTEN; MOON, 2008). A empresa sustentável "é a que procura incorporar os conceitos e objetivos relacionados com o desenvolvimento sustentável em suas políticas e práticas de modo consistente" (BARBIERI; CAJAZEIRA, 2009, p. 70).

A sustentabilidade requer um repensar da noção de sucesso empresarial, desempenho organizacional e um esclarecimento sobre o seu significado para o negócio e para a sociedade em geral (KRAMAR; HARIADI, 2010). Gladwin, Kennelly e Krause (1995) identificam 

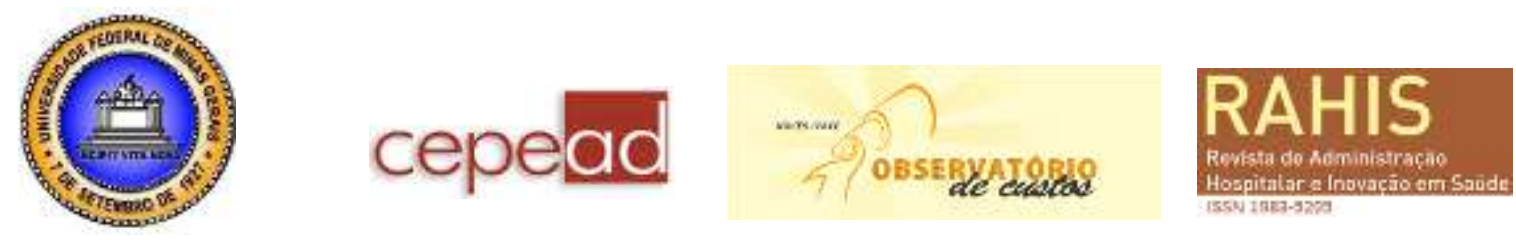

componentes compartilhados por diferentes correntes de sustentabilidade. Para eles, cinco requisitos são fundamentais para a sustentabilidade. São eles:

- Inclusão: desenvolvimento tanto do sistema humano quanto do sistema ambiental ao longo do tempo. Inclui a eficiência social e econômica em uma inter-relação com a ecológica;

- Conectividade: visão sistêmica que reconhece a interdependência ecológica, social e econômica entre o todo;

- Equidade: racionalidade na distribuição dos recursos, intergeracional, intrageracional e entre as espécies;

- Prudência: cautela e precaução;

- Segurança: assegurar a saúde e a qualidade de vida de todas as gerações, diminuição das incertezas quanto aos danos ao ecossistema.

Embora exista um consenso entre os defensores do desenvolvimento sustentável de que a sociedade precisa mudar, os debates giram em torno de perspectivas políticas e filosóficas já existentes, não possibilitando uma filosofia unificada para tal abordagem. Existe, ainda, uma divisão entre os partidários do 'status quo' e a abordagem do desenvolvimento sustentável (HOPWOOD; MELLOR; O’BRIEN, 2005).

De acordo com Hopwood, Mellor e O'brien (2005), a abordagem do 'status quo' postula a mudança por meio de uma gestão de cima para baixo, utilizando-se das estruturas existentes de tomada de decisão, que se dá principalmente pela ação política de trabalho dentro e fora das atuais estruturas de poder. Segundo eles, nem o ambiente nem a sociedade deverão se ajustar para enfrentar os problemas ambientais, pois os mercados e a tecnologia darão conta do crescimento econômico necessário ao desenvolvimento.

Quanto ao desenvolvimento sustentável, o modelo mais usual trata da relação entre as esferas de ambiente, sociedade e economia, considerando que, mesmo conectadas, em alguma parte uma independe da outra. A alternativa sugerida pelos adeptos de um discurso verde mais radical partilha a redução do nível de vida e de consumo.

Já os reformadores concentram-se na ciência e na informação, aceitando que grandes mudanças na política e no estilo de vida serão necessárias em algum ponto, mas que estas sejam alcançadas com o tempo, principalmente quando os governos e organizações introduzirem tais reformas. Os transformacionistas argumentam que a degradação ambiental, a pobreza e a falta de justiça estão enraizadas na sociedade baseada na dominação e exploração do meio ambiente e, sendo assim, uma transformação da sociedade e das relações humanas com o meio ambiente é necessária para evitar crises e um possível colapso do ecossistema (HOPWOOD; MELLOR; O'BRIEN, 2005).

Elkington (2001) apresentou a ideia do tripé da sustentabilidade, 'Triple Bottom Line' (TBL), objetivando medir o desempenho financeiro, social e ambiental das empresas durante um período de tempo. Essa concepção propõe às organizações a integração de três dimensões: social, ambiental e econômica, postulando que organização sustentável é aquela que consegue bons resultados nas três dimensões. Tal abordagem tornou-se dominante no paradigma mais atual da sustentabilidade.

Para Shrivastava (1995) a inserção da sustentabilidade no contexto das organizações representa uma mudança de posicionamento em um princípio central da Administração, a mudança do foco econômico para o ecológico. $\mathrm{O}$ autor propõe substituir o modelo organizacional baseado no antropocentrismo por um modelo ecocêntrico de administração. Conforme suas palavras, "[...] exige a adoção de teoria gerencial que não é antropocêntrica, uma teoria que reconheça o risco e a degradação ecológica como variável central na análise organizacional” (SHRIVASTAVA, 1995, p.133). 

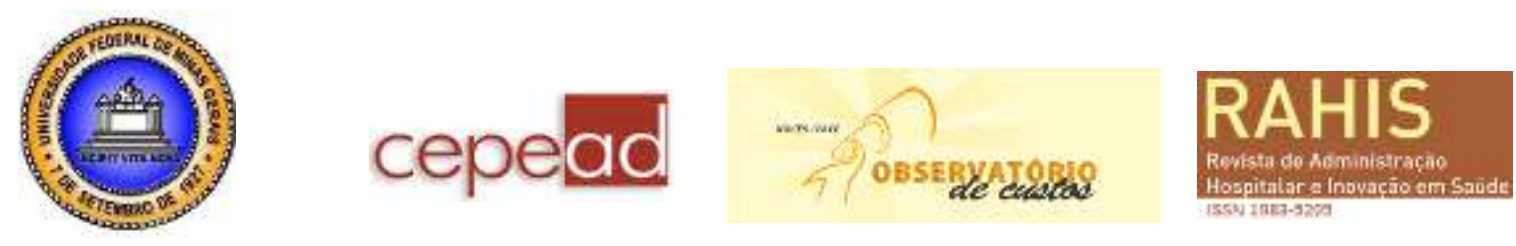

Nos estudos de administração com enfoque em sustentabilidade predominam tentativas de analisar as organizações sob a ótica das principais perspectivas ambientalistas, a fim de prescrever processos e práticas que correspondam com a sustentabilidade ecoambiental (GLADWIN; KENNELLY; KRAUSE, 1995; SHRIVASTAVA, 1995). Correspondente ao desenrolar do desenvolvimento sustentável como um conceito, hoje a visão gerencial defende os benefícios da gestão ambiental proativa, enquanto programas institucionais para as relações da comunidade, gestão de produtos, de prevenção da poluição e liderança ambiental como sendo coerentes com os objetivos de aumentar o capital próprio (PEREIRA et al, 2012).

Amaral e La Rovere (2003) salientam que a organização pode usar indicadores da ecoeficiência, tais como, o consumo da energia, a água, o uso dos materiais, efluentes e resíduos. O uso de indicadores ambientais, sociais, e econômicos melhora os processos de tomada de decisão de modo que as definições em projetos e as ações ligadas ao negócio possam ter uma base mais contínua e características mais sustentáveis.

Na prática, percebe-se nas organizações a transformação dos conceitos em indicadores e números, numa tentativa de quantificar e rentabilizar as perspectivas da sustentabilidade abordadas. Um exemplo de tal abordagem, largamente utilizado devido à abrangência que alcança, é a ‘-Global Reporting Initiative-(GRI), que criou uma metodologia para concepção de uma série de indicadores a serem usados em relatórios de sustentabilidade, que permitem medir o desempenho organizacional e fazer comparações ao longo do tempo (GRI, 2013).

No entanto, existe dificuldade na quantificação das dimensões ambientais e sociais do desempenho organizacional (SCHILIZZI, 2002). As organizações e pesquisadores ainda buscam métricas na tentativa de capturar "os valores" que compõem cada dimensão da sustentabilidade, a fim de apontar um norte para as organizações (LINGANE; OLSEN, 2004).

Correspondente ao desenrolar do desenvolvimento sustentável como um conceito, hoje a visão gerencial defende os benefícios da gestão ambiental proativa, enquanto programas institucionais para as relações da comunidade, gestão de produtos, de prevenção da poluição, e liderança ambiental como sendo coerentes com os objetivos de aumentar o capital próprio (PEREIRA et al, 2012).

Empenhadas em formular propostas de gestão que sejam condizentes com os objetivos do desenvolvimento sustentável, as organizações buscam novos modelos de gestão que procuram "reduzir a quantidade de materiais e energia por bem ou serviço produzido, substituir insumos obtidos de recursos naturais não renováveis por insumos provenientes de recursos renováveis e eliminar substâncias tóxicas, entre outras providências" (BARBIERI; CAJAZEIRA, 2009, p.73).

Nesse contexto, Jabbour e Santos (2006) sugerem um modelo que realiza uma sistematização de estágios evolutivos da gestão ambiental empresarial, sendo eles: a especialização funcional (área de gestão ambiental voltada exclusivamente para o atendimento da legislação e isolada do contexto organizacional); integração interna (no qual cresce o engajamento das demais áreas funcionais na gestão ambiental, mas a dimensão ainda não é tida como estratégica); integração externa (estágio em que todas as áreas da empresa buscam sistematicamente explorar vantagens competitivas por meio da gestão ambiental). Cabe ressaltar que as organizações tendem a não apresentar um comportamento linear, porém apesar de possuírem características predominantes de um dado estágio, não precisam estar rigidamente confinadas a ele.

Além disso, ao implantar estratégias sustentáveis, como o controle de poluição, o uso de energias limpas e as novas tecnologias, as organizações melhoram sua imagem pública, 

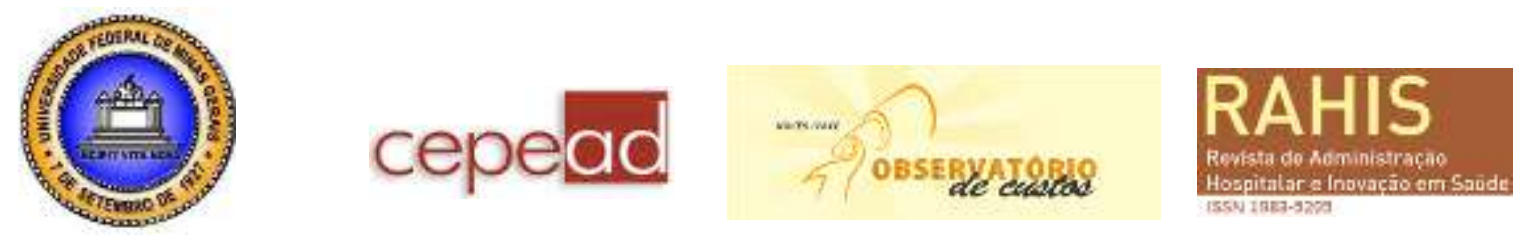

enquanto a alta administração da empresa torna-se mais pró-ativa em seus esforços ambientais, e os seus sistemas de valores pessoais refletem níveis mais elevados de preocupação ambiental (ANDERSSON; BATEMAN, 2000; DUTTON; ASHFORD, 1993).

Shrivastava e Hart (1998) postulam que as empresas que adotarem as medidas de sustentabilidade, terão seu ciclo de vida ampliado e contribuirão com a criação de um mundo mais sustentável. Ao levantar diversos estudos sobre a temática, esses mesmos autores encontraram algumas dimensões essenciais para uma gestão sustentável nas organizações, que são: missão; estratégias empresariais e competitivas; competências essenciais; estruturas e sistemas; cultura e processos organizacionais e critérios de desempenho. Eles argumentam que para que a empresa realmente adote a sustentabilidade, essas dimensões devem ser coerentes nas suas inter-relações e devem ter foco no desempenho socioambiental da organização.

Todo esse processo de ambientalização do setor empresarial, incentivado pela emergência das preocupações com a sustentabilidade, impulsionou a necessidade da conscientização acerca da corresponsabilidade de todos os atores envolvidos, uma vez que seus comportamentos individuais e práticas cotidianas acabam por interferir na gestão das organizações e na busca por padrões que se mostrem mais sustentáveis.

\section{Resíduos de Serviços de Saúde}

Os Resíduos de Serviços de Saúde (RSS) são aqueles gerados em qualquer atividade de natureza médico-assistencial humana ou animal, como: hospitais, clínicas odontológicas, veterinárias, farmácias, centros de pesquisa, necrotérios, funerárias, medicina legal e barreiras sanitárias (BRASIL, 2006).

Devido às suas características biológicas, químicas e físicas, os RSS, quando gerenciados de forma inadequada, provocam risco à saúde humana e ao meio ambiente (BRASIL, 2006; CORREAA; LUNARDI; DE CONTO, 2007). Entretanto, a possibilidade de contaminação do meio ambiente, pacientes, funcionários e comunidade em geral por tais resíduos pode ser considerada inexistente se medidas básicas de manejo e controle forem devidamente aplicadas (PEREIRA; LUCENA; FERNANDES, 2010).

Os RSS foram classificados pela ABNT NBR no 12.808/1993 (MADERS; CASTRO, 2010), sendo posteriormente classificados de forma mais detalhada pela RDC $n^{\circ}$ 306/2004 e pela Resolução no 358 do CONAMA, que distribui os RSS em 05 (cinco) grupos: A, B, C, D e E. O descarte dos RSS é de responsabilidade do gerador e exigem um gerenciamento complexo em função de sua composição (BRASIL, 2004). Existem diversos procedimentos com o objetivo de minimizar a produção de resíduos e proporcionar aos resíduos provenientes de estabelecimentos de saúde um encaminhamento seguro, de forma eficiente, visando à proteção dos trabalhadores e à preservação da saúde pública, dos recursos naturais e do meio ambiente (BRASIL, 2006; MONTEIRO, 2001).

Os cinco grupos dos RSS estão descritos a seguir, de acordo com a Resolução CONAMA n ${ }^{\circ} 358$ (BRASIL, 2005).

- Grupo A: são os resíduos que representam risco potencial para a saúde pública e ao meio ambiente devido à presença de agentes biológicos. Dentro desse grupo está o sangue, hemoderivados, animais usados em experimentação, materiais que tenham entrado em contato com excreções, secreções, tecidos, órgãos, fetos, vísceras e peças anatômicas; resíduos de fabricação de produtos biológicos; filtros de ar e gases aspirados de área contaminada; membrana filtrante de equipamento médico hospitalar; 
materiais perfurocortantes ou escarificantes. Este grupo divide-se em algumas categorias, tais como, A1, A2, A3, A4 e A5, conforme descrito no Quadro 01.

Quadro 01 - Subgrupos de resíduos A e descrições

\begin{tabular}{|c|c|}
\hline $\begin{array}{l}\text { Subgrupos do } \\
\text { grupo A }\end{array}$ & Conteúdo \\
\hline A1 & $\begin{array}{l}\text { 1. Culturas e estoques de microrganismos; resíduos de fabricação de produtos biológicos, } \\
\text { exceto os hemoderivados; descarte de vacinas de microrganismos vivos ou atenuados; } \\
\text { meios de cultura e instrumentais utilizados para transferência, inoculação ou mistura de } \\
\text { culturas; resíduos de laboratórios de manipulação genética; 2. Resíduos resultantes da } \\
\text { atenção à saúde de indivíduos ou animais, com suspeita ou certeza de contaminação } \\
\text { biológica por agentes Classe de risco 4, microrganismos com relevância epidemiológica e } \\
\text { risco de disseminação ou causador de doença emergente que se torne epidemiologicamente } \\
\text { importante ou cujo mecanismo de transmissão seja desconhecido; 3. Bolsas transfusionais } \\
\text { contendo sangue ou hemocomponentes rejeitadas por contaminação ou por má } \\
\text { conservação, ou com prazo de validade vencido, e aquelas oriundas de coleta incompleta; } \\
\text { 4. Sobras de amostras de laboratório contendo sangue ou líquidos corpóreos, recipientes e } \\
\text { materiais resultantes do processo de assistência à saúde, contendo sangue ou líquidos } \\
\text { corpóreos na forma livre. }\end{array}$ \\
\hline A2 & $\begin{array}{l}\text { Carcaças, peças anatômicas, vísceras e outros resíduos provenientes de animais submetidos } \\
\text { a processos de experimentação com inoculação de microorganismos, bem como suas } \\
\text { forrações, e os cadáveres de animais suspeitos de serem portadores de microrganismos de } \\
\text { relevância epidemiológica e com risco de disseminação, que foram submetidos ou não a } \\
\text { estudo anátomo-patológico ou confirmação diagnóstica. }\end{array}$ \\
\hline $\mathbf{A 3}$ & $\begin{array}{l}\text { Peças anatômicas (membros) do ser humano; produto de fecundação sem sinais vitais, com } \\
\text { peso menor que } 500 \text { gramas ou estatura menor que } 25 \mathrm{~cm} \text { ou idade gestacional menor que } \\
20 \text { semanas, que não tenham valor científico ou legal e não tenha havido requisição pelo } \\
\text { paciente ou familiares. }\end{array}$ \\
\hline A4 & $\begin{array}{l}\text { 1. Kits de linhas arteriais, endovenosas e dialisadores, quando descartados; } 2 \text {. Filtros de ar } \\
\text { e gases aspirados de área contaminada; membrana filtrante de equipamento médico } \\
\text { hospitalar e de pesquisa, entre outros similares; } 3 \text {. Sobras de amostras de laboratório e seus } \\
\text { recipientes contendo fezes, urina e secreções, provenientes de pacientes que não } \\
\text { contenham e nem sejam suspeitos de conter agentes Classe de Risco } 4 \text {, e nem apresentem } \\
\text { relevância epidemiológica e risco de disseminação, ou microrganismo causador de doença } \\
\text { emergente que se torne epidemiologicamente importante ou cujo mecanismo de } \\
\text { transmissão seja desconhecido ou com suspeita de contaminação com príons; } 4 \text {. Resíduos } \\
\text { de tecido adiposo proveniente de lipoaspiração, lipoescultura ou outro procedimento de } \\
\text { cirurgia plástica que gere este tipo de resíduo; 5. Recipientes e materiais resultantes do } \\
\text { processo de assistência à saúde, que não contenha sangue ou líquidos corpóreos na forma } \\
\text { livre; 6. Peças anatômicas (órgãos e tecidos) e outros resíduos provenientes de } \\
\text { procedimentos cirúrgicos ou de estudos anátomo-patológicos ou de confirmação } \\
\text { diagnóstica; 7. Carcaças, peças anatômicas, vísceras e outros resíduos provenientes de } \\
\text { animais não submetidos a processos de experimentação com inoculação de } \\
\text { microorganismos, bem como suas forrações; e } 8 \text {. Bolsas transfusionais vazias ou com } \\
\text { volume residual pós-transfusão. }\end{array}$ \\
\hline A5 & $\begin{array}{l}\text { Órgãos, tecidos, fluidos orgânicos, materiais perfurocortantes ou escarificantes e demais } \\
\text { materiais resultantes da atenção à saúde de indivíduos ou animais, com suspeita ou certeza } \\
\text { de contaminação com príons. }\end{array}$ \\
\hline
\end{tabular}

Fonte: Resolução CONAMA n 358 (BRASIL, 2005, p. 619 - 620).

- Grupo B: Resíduos contendo substâncias químicas que podem apresentar risco à saúde pública ou ao meio ambiente, dependendo de suas características de inflamabilidade, corrosividade, reatividade e toxicidade. Neste grupo se encaixam os produtos hormonais e produtos antimicrobianos; os resíduos e insumos farmacêuticos dos 

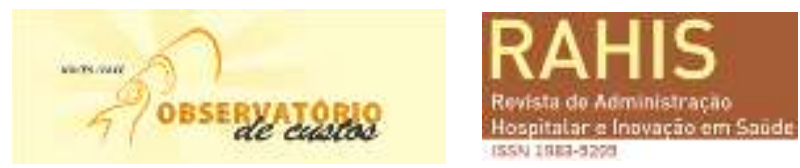

medicamentos controlados; resíduos de saneantes, desinfetantes, resíduos contendo metais pesados; reagentes para laboratório.

- Grupo C: Materiais resultantes de atividades humanas que contenham radionuclídeos em quantidades superiores aos limites de eliminação. São os materiais resultantes dos serviços de medicina nuclear e radioterapia.

- Grupo D: São os resíduos equiparados aos domiciliares por não apresentem risco biológico, químico ou radiológico à saúde ou ao meio ambiente. Compreende papel, absorventes, peças descartáveis de vestuário, resto alimentar, resíduos de varrição e gesso provenientes de assistência à saúde.

- Grupo E: Materiais perfurocortantes ou escarificantes, tais como: lâminas de barbear, agulhas, ampolas de vidro, brocas, bisturi; espátulas; e todos os utensílios de vidro quebrados no laboratório.

Os procedimentos para descarte estão dispostos nas resoluções do CONAMA ${ }^{\circ}$ 358/05 e RDC ANVISA $n^{\circ}$ 306/04, que dispõem respectivamente sobre o tratamento e disposição final dos resíduos e o Regulamento Técnico para o gerenciamento de RSS. Segundo Coelho (2007), a Resolução RDC $n^{\circ} 306$ registrou no artigo $4^{\circ}$, que a inobservação do disposto nessa Resolução e no Regulamento Técnico, constitui-se infração sanitária e o infrator estará sujeito às penalidades previstas em lei.

Dentre os acidentes ocupacionais que podem ocorrer nas instituições de saúde, destacam-se aqueles ocasionados por materiais perfurocortantes, principalmente por acidentes com agulhas durante o recapeamento, envolvendo trabalhadores de enfermagem e os profissionais da higiene durante o trabalho na limpeza, coleta ou transporte dos resíduos. A prevenção da exposição ao sangue ou a outros materiais biológicos é capaz de evitar a transmissão do HIV, dos vírus da Hepatite $\mathrm{B}$ e C, e de outras patologias, minimizando o risco às pessoas que manipulam os resíduos de serviços de saúde (COELHO, 2007).

Além desses, outros desafios são enfrentados em relação à problemática. Na medida em que o volume de resíduos nos depósitos está crescendo, aumentam os custos e surgem maiores dificuldades de áreas ambientalmente seguras, disponíveis para recebê-los. Dessa forma, é necessária a minimização da geração e métodos de tratamento que tenham como objetivo diminuir o volume dos resíduos a serem dispostos no solo (BRASIL, 2006).

Os resíduos sólidos são compostos de materiais passíveis de recuperação. Tal recuperação, além de gerar trabalho e renda, proporciona a redução de extração de recursos naturais e economia da energia necessária à extração e beneficiamento dos mesmos. Nesse sentido, sua gestão passou a ser condição indispensável para se atingir o desenvolvimento sustentável (Ibidem).

A gestão sustentável dos resíduos sólidos vem ao encontro do princípio dos 3Rs, apresentado na Agenda 21: redução do uso de matérias-primas e energia, reutilização dos produtos e reciclagem (Ibidem).

Para atingir tal meta, é imprescindível a implantação de uma eficiente coleta seletiva e reciclar o material, uma vez que a reciclagem polui menos, pois diminui o volume de resíduos a serem descartados (Ibidem).

Contudo, a questão da disposição final ambientalmente segura dos resíduos ainda perdura, uma vez que segundo Moreschi (2013), diante das novas tendências de consumo, a partir da segunda metade do século XX, houve um aumento sucessivo na produção de resíduos, o qual tem ultrapassado a capacidade de absorção da natureza. 


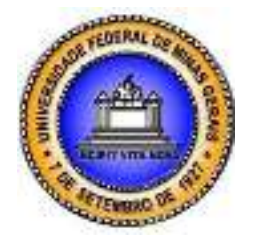

\section{Método}

Para atingir os objetivos propostos realizou-se uma pesquisa exploratória de caráter qualitativo (GIL, 2010), cuja base teórica para o trabalho emanou de pesquisas bibliográficas. A estratégia utilizada foi o estudo de caso, por permitir examinar aspectos variados do problema em seu contexto real, assegurando uma melhor compreensão da realidade (YIN, 2010).

O método qualitativo foi escolhido por se debruçar sobre um nível de realidade que não pode ser quantificado e por trabalhar com uma série de significados tais como: motivações, aspirações, crenças, valores e atitudes (MINAYO; SANCHES, 1993).

Atendendo a um dos princípios de coleta de dados de Yin (2010), foram utilizadas diferentes fontes de evidências. Assim, foram utilizadas fontes de dados primários e secundários (COOPER; SHINDLER, 2011). Os dados primários foram obtidos por meio de entrevistas e observação. Os dados secundários foram obtidos por meio de documentos institucionais e site da empresa, os quais serviram para embasar o trabalho e caracterizar a instituição, seus setores e serviços.

Para as entrevistas optou-se por um roteiro semiestruturado, elaborado com base nos autores mencionados no quadro teórico de referência. Como parte do protocolo de coleta de dados, o roteiro forneceu aos entrevistadores liberdade para desenvolver os questionamentos em qualquer direção que os mesmos considerassem adequados (MARCONI; LAKATOS, 2005; GIL 2010).

As entrevistas foram realizadas com o gerente administrativo, o gerente comercial e o engenheiro químico da empresa, todos responsáveis pelo nível tático da empresa. As entrevistas foram realizadas entre os dias 12 e 19 de julho de 2013, totalizando 03 entrevistas, que foram gravadas em áudio para posterior análise. O material coletado nas entrevistas foi ouvido várias vezes, visando-se obter o perfeito significado das falas. As vocalizações foram transcritas em editor de texto de forma contínua, sem alterar a sua sequência, a fim de facilitar sua análise e entendimento. Para a análise desse material, foi realizada uma organização das falas pelas informações semelhantes, bem como pela diferenciação. Essa etapa teve o propósito de identificar o conteúdo apresentado pelos entrevistados, o qual foi, em seguida, exposto no texto em forma de resultados.

O procedimento da amostragem foi não probabilístico por conveniência e tipicidade. $\mathrm{Na}$ amostragem por conveniência os indivíduos foram selecionados a partir da acessibilidade dos pesquisadores (VERGARA, 2007). Já a amostragem por tipicidade é constituída pela seleção de elementos considerados pelo pesquisador como representativos. Dessa forma, a amostragem por acessibilidade conduziu a coleta dos dados referentes a assuntos de conhecimento de todos os colaboradores e a amostragem por tipicidade foi utilizada para a coleta dos dados de conhecimento mais profundo por parte dos gerentes e engenheiro químico da empresa.

A técnica de observação utilizada é classificada, segundo Gil (2010), como observação simples, uma vez que foi feita a observação espontânea dos fatos sem produzir querelas ou suspeitas nos membros da organização.

Este estudo de caso foi realizado em uma filial de uma empresa multinacional, localizada no interior do Estado do Rio Grande do Sul, cuja atividade é a destinação final de resíduos especiais, tais como: materiais infectantes, medicamentos, objetos perfurantes e cortantes, vacinas, produtos químicos, entre outros resíduos de risco, que necessitam de um acondicionamento adequado. 

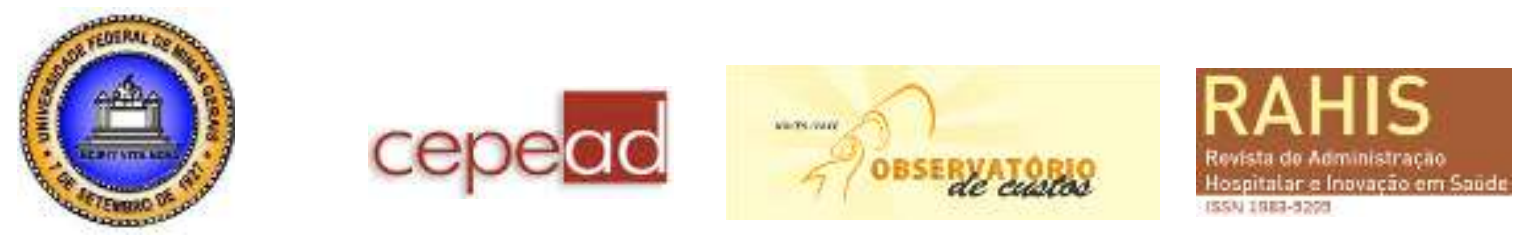

A escolha dessa organização deveu-se aos seguintes fatores: (i) trabalhar na coleta de resíduos especiais; (ii) estar preocupada com a diminuição do risco de tais resíduos; (iii) estar comprometida com questões sustentáveis e com a redução do impacto ambiental; e, (iv) facilidade de acesso (SILVA; IOP; SCHERER, 2010; SILVA; IOP, 2012).

As dimensões analisadas no presente estudo referem-se à sustentabilidade, composta pelas subcategorias: especificidades da coleta e a gestão dos resíduos de serviços de saúde (RSS) e as estratégias e ações para a sustentabilidade.

A análise e interpretação dos dados foi realizada de forma descritiva, analisando-se criteriosamente as respostas obtidas dos entrevistados e, comparando-as com a literatura existente.

\section{Análise dos resultados}

\section{Caracterização da Empresa}

A empresa pesquisada trata-se de uma multinacional, líder de mercado em potências mundiais como EUA, Reino Unido e Canadá, sendo considerada a maior empresa do mundo no tratamento de resíduos de saúde, com atuação em 15 países e atendendo a mais de 150 mil clientes. A principal forma de crescimento dessa organização no mercado se dá através de aquisições, já que ela dificilmente entra em concorrência direta.

No Brasil, a organização iniciou suas atividades em 2010 e desde então já adquiriu 12 empresas de menor porte, possuindo atualmente 16 unidades espalhadas pelo país. Nesse contexto, insere-se a filial em estudo, que está instalada em um município do interior do Estado do Rio Grande do Sul.

Essa filial foi inaugurada em 2001, com o propósito de tratamento de resíduos de saúde e adquirida pela multinacional em outubro de 2010. O quadro de colaboradores atual é composto por 47 funcionários, distribuídos entre a área administrativa e operacional em todo o Estado do Rio Grande do Sul (RS). A empresa abrange aproximadamente 250 cidades entre o Estado do RS e algumas cidades de Santa Catarina, que fazem fronteira com o RS, prestando serviços advindos da coleta até a destinação final dos RSS, compreendendo cinco mil e trezentos clientes.

A empresa busca minimizar os efeitos dos resíduos e reduzir o impacto ambiental. Para tanto, trabalha para desenvolver novas estratégias para a segregação dos resíduos e minimização de riscos. Além disso, são oferecidos seguros e serviços de treinamento de resíduos, pois os clientes de saúde dependem dos processos para ajudar a manter os funcionários em segurança. Dentre os principais clientes da organização inserem-se os hospitais, consultórios médicos e a indústria farmacêutica através de programa de logística reversa.

\section{Especificidades da coleta e a gestão dos resíduos de serviços de saúde (RSS)}

Desde sua fundação, a empresa reconheceu a gestão adequada dos resíduos hospitalares como um serviço de sustentabilidade em si. Seus serviços incluem a coleta e o transporte de resíduos perigosos (hospitalares e industriais), o tratamento e a destinação final. Os resíduos são embalados e transportados de forma a ter o mínimo contato com o coletor. A coleta dos resíduos é feita de forma mecanizada e diretamente no cliente, atendendo uma programação pré-definida, estabelecida entre empresa e cliente. 

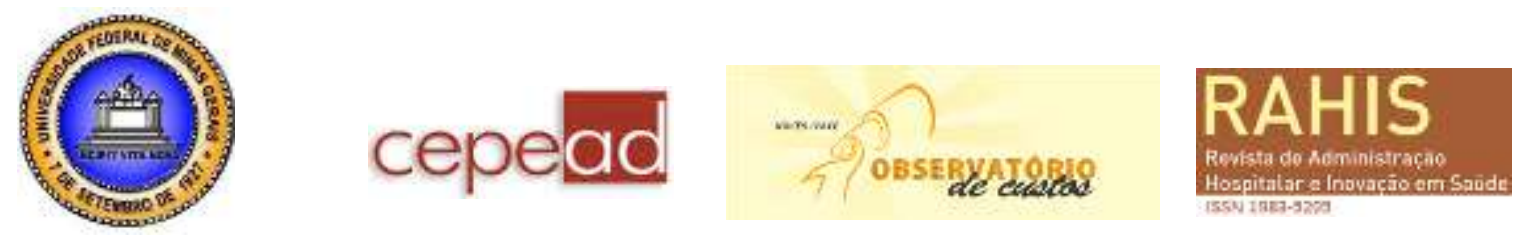

Ressalta-se que os tipos de resíduos coletados pela empresa nas organizações de saúde encontram-se predominantemente nos grupos A, A1, A2, B e E, de acordo com a Resolução $n^{\circ} 358 / 2005$ do CONAMA.

No procedimento de coleta, os resíduos do sistema de saúde são embalados em bombonas de termoplásticos, com os devidos reforços para manuseio e transporte, previamente enviadas para os geradores. A preparação e o acondicionamento são executados pelo próprio gerador, garantindo o mínimo contato dos coletores e a não exposição dos RSS.

Após a utilização e a remoção do seu conteúdo, as bombonas são higienizadas com produtos bactericidas a base de cloro e novamente encaminhadas às unidades de saúde para reutilização. A coleta dos resíduos nas unidades de saúde, devidamente acondicionados nas bombonas, é executada de forma mecanizada, atendendo a programação pré-definida e as frequências estabelecidas entre a empresa e o gerador do resíduo, garantindo formas adequadas e seguras para o seu manuseio.

Depois de acondicionados em recipientes, de acordo com sua tipologia, os resíduos são transportados por veículos devidamente preparados e identificados, seguindo roteiros prédeterminados, com motoristas treinados em transporte de cargas perigosas.

A filial do interior do RS possui autoclaves, que executam um método de tratamento que consiste na aplicação de vapor saturado sob pressão, garantindo condições de temperatura, pressão e tempo de exposição adequado à inativação dos microorganismos presentes. Depois de esterilizados, os resíduos são dispostos em aterro sanitário.

As autoclaves possuem uma tecnologia destinada ao tratamento dos resíduos do grupo A e E, com $40 \%$ de redução do volume dos RSS. Além do processo de autoclavagem, a empresa adquiriu recentemente um incinerador, projetado para incinerar resíduos de maneira limpa e segura, sem causar danos ao meio ambiente, pois é composto de duas câmaras de combustão (primária e secundária), revestidas com material refratário e de isolamento, compatíveis com as temperaturas praticadas.

O processo de incineração obedece integralmente à Resolução CONAMA no 316/02, sendo seus equipamentos dotados de analisadores contínuos de emissões gasosas e sistema de intertratamento. $\mathrm{O}$ tempo de residência dos gases na câmara secundária é de 2 segundos. Depois da queima, os gases são submetidos a um resfriamento brusco, através de torres de lavagem. Os líquidos utilizados no processo de lavagem são destruídos no próprio equipamento, num circuito fechado.

Os líquidos gerados nos processos de higienização das bombonas e carros de coleta, bem como no processo de autoclavagem são conduzidos para um depósito de efluentes líquidos. Esses efluentes são posteriormente introduzidos na primeira câmara do incinerador, para controle de temperatura, sendo nesse local destruídos.

Os efluentes gerados pelo processo de esterilização dos RSS são provenientes da condensação do vapor e de outros resíduos líquidos colocados na autoclave, tais como, sangue e hemoderivados, secreções e líquidos orgânicos.

Apesar de prestar serviços de coleta, transporte, tratamento e destinação final ao lixo hospitalar de organizações da saúde, alguns resíduos não são direcionados para o aterro próprio da empresa. Dessa forma, essa filial do RS possui 8 hectares, onde são aterrados alguns grupos de resíduos, porém determinados grupos de risco, após o tratamento e autoclavagem, têm sua destinação final para outros locais mais apropriados, conforme as leis de regulamentação, já que o incinerador adquirido recentemente está iniciando suas atividades. 

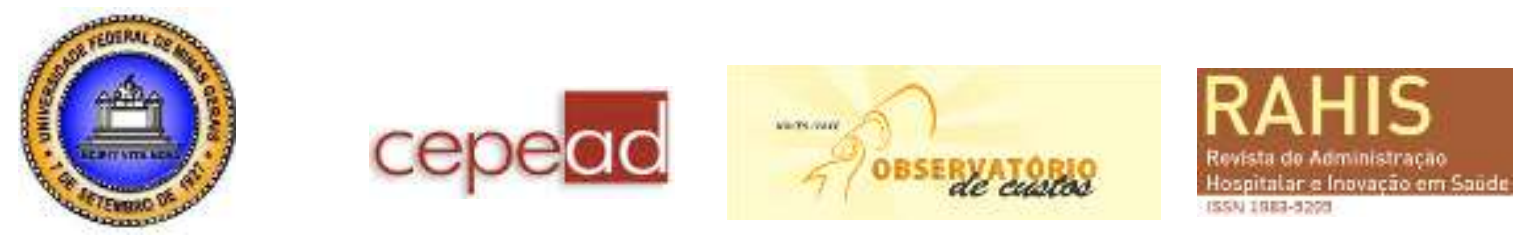

\section{Estratégias e Ações para a Sustentabilidade}

Dentre as principais diretrizes da empresa, destaca-se a procura em atender ao mercado de resíduos especiais, a fim de diminuir o impacto gerado através de um destino adequado aos resíduos, obtendo um aperfeiçoamento e segurança nos trabalhos executados, bem como garantindo que sejam atendidas as legislações vigentes.

Verificou-se que a organização em questão possui uma missão que demonstra preocupação com a segurança e os riscos que os resíduos de serviços de saúde podem gerar para a sociedade, conforme segue: "Combinar soluções integradas com excelência na prestação de serviço ao cliente promovendo a segurança, conformidade e gestão de riscos para nossos clientes".

A análise da orientação estratégica da empresa permite identificar a inexistência de um planejamento voltado para o desenvolvimento sustentável formalmente definido, tomando como base a legislação ambiental para proceder as suas atividades e para que possa definir o seu programa de gestão. As políticas de gestão ambiental das organizações podem ser motivadas por fatores classificados em dois grupos, tais como: (i) os fatores externos relativos aos governos, legislação ambiental, público consumidor, acionistas, movimentos ambientalistas e instituições financeiras; e (ii) os fatores internos, referentes à economia, advinda da redução de desperdício ou reciclagem, menor consumo de energia e substituição de insumos (ASHLEY, 2003).

Desse modo, apesar de não existirem definições formais, a questão ambiental, especialmente no que se refere à saúde no ambiente de trabalho, constitui-se em uma preocupação do corpo diretivo da organização, pois os funcionários da área operacional estão suscetíveis à contaminação e doenças.

Além disso, verificou-se que a empresa costuma utilizar seus recursos de modo planejado, com o intuito da preservação ambiental, gerando benefícios para a sociedade. Contudo, corroborando os estudos de Hawken et al. (2000), abaixo abordam-se algumas ações da organização em estudo voltadas para a sustentabilidade, de acordo com medidas relacionadas à redução no uso de recursos, o biomimetismo, mudança nos padrões de consumo e investimento no capital natural.

$>$ Redução no uso de recursos: Um exemplo, no setor administrativo, são as práticas de conscientização sobre a utilização de energia elétrica e estabilizadores, solicitando o desligamento quando não mais utilizados, bem como as impressões frente e verso, economizando folhas, além de separação de papéis brancos e coloridos, que são vendidos para a reciclagem. As embalagens que transportam os resíduos de saúde não podem ser reutilizadas devido à contaminação, sendo autoclavados juntamente com os resíduos transportados. Já as bombonas que transportam resíduos de classe A2 e A3 são reutilizáveis após desinfecção, bem como os contêineres. Para esse tipo de RSS não se tem por prática fazer reciclagem, devido às suas especificidades.

$>$ Biomimetismo: não há retorno de resíduos, sendo os mesmos encaminhados para aterros devidamente licenciados. $\mathrm{Na}$ usina de tratamento a organização possui o processo de autoclavagem, onde são gerados efluentes durante o tratamento dos resíduos que são tratados em uma Estação de Tratamento de Efluente (ETE), visando atender os parâmetros da legislação para lançamento (destinação) do mesmo. A empresa utiliza Gás Liquefeito de Petróleo (GLP) na alimentação da caldeira (emissão de poluente baixa), pois se busca não utilizar lenha como combustível para esta 


\section{cepead}
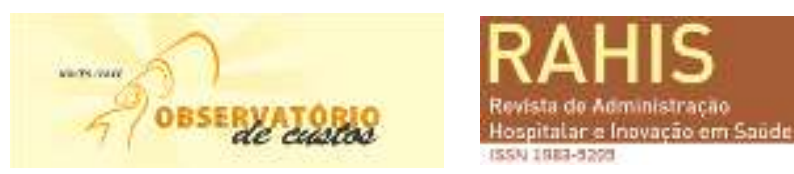

caldeira, apesar do custo ser consideravelmente menor, mas ambientalmente um agravante. Optou-se por essa substituição devido à política de preservação ambiental.

$>$ Mudança nos padrões de consumo: a organização utiliza aterros de empresas devidamente licenciadas para a destinação final de resíduos dos grupos A, B e E, demonstrando a substituição de investimento de capital próprio;

$>$ Investimento no capital natural: o local de instalação da Usina que possibilita o tratamento e a destinação final de determinados resíduos é constantemente avaliado por órgãos legisladores, por se tratar do manuseio com resíduos de saúde (infectantes), bem como valas para aterramento desses resíduos, após o tratamento. Essas valas possuem diversas camadas, compostas por geomembrana e cal, que impossibilitam os resíduos aterrados entrar em contato com o lençol freático. A cada três meses se faz uma coleta para verificar se não houve nenhum tipo de vazamento e contaminação. Cabe salientar que na Usina não há emissão de gases poluentes e que os resíduos aterrados passam por amplo tratamento e esterilização, portanto, não há riscos para a comunidade.

Com relação às práticas de gestão ambiental, a empresa realiza fiscalização interna, execução de teste de monitoramento ambiental na área da Usina, com análises da água subterrânea, testes de controle de esterilização, controle de manutenção das máquinas e relatórios de coletas e recebimento de RSS, atendendo a conformidade de manuseio dos resíduos biológicos.

Observou-se que o enfoque reativo adotado pela organização, visto que a maioria das ações definidas para solucionar problemas de agressão ao meio ambiente têm sido implementadas mais por exigência legal do que por sensibilização prévia de seus administradores.

No Quadro 02 demonstram-se as dimensões chaves para uma gestão ambiental sustentável e a identificação da aplicabilidade nas questões relacionadas à empresa em estudo, conforme estudos de Shrivastava e Hart (1998).

Quadro 02 - Dimensões chaves para a gestão ambiental sustentável

\begin{tabular}{|c|c|}
\hline Dimensões & Aplicação das Dimensões \\
\hline Missão & $\begin{array}{l}\text { Combinar soluções integradas com excelência na prestação serviço ao cliente } \\
\text { promovendo a segurança, conformidade e gestão de riscos para nossos clientes. }\end{array}$ \\
\hline $\begin{array}{l}\text { Estratégias } \\
\text { empresariais e } \\
\text { competitivas }\end{array}$ & $\begin{array}{l}\text { Cinco estratégias empresariais para com o seu acionista e cliente, tais como, criação de } \\
\text { valor ao acionista, valor ao cliente, valor aos membros, crescimento e liderança. A } \\
\text { principal forma de crescimento da empresa no mercado pelo mundo é através de } \\
\text { aquisições e o foco são os resíduos de serviços de saúde. }\end{array}$ \\
\hline $\begin{array}{l}\text { Competências } \\
\text { essenciais }\end{array}$ & Coleta, transporte, tratamento e destinação final de resíduos de serviços de saúde (RSS) \\
\hline Estrutura e sistemas & $\begin{array}{l}\text { Mecanismos de controle são geridos através de banco de dados, utilizando software de } \\
\text { gestão, que auxilia o sistema de coleta baseado na implantação de rotas, com emissões } \\
\text { de planilhas semanais, descrevendo os estabelecimentos a serem coletados na semana. }\end{array}$ \\
\hline $\begin{array}{c}\text { Cultura e processos } \\
\text { organizacionais }\end{array}$ & $\begin{array}{l}\text { As equipes e funções são integradas e coordenadas pelo sistema de gestão. Ações de } \\
\text { treinamento são realizadas de acordo com a necessidade, por meio de programas de } \\
\text { prevenção de acidentes e manuseio de RSS proporcionado aos clientes e colaboradores. }\end{array}$ \\
\hline $\begin{array}{l}\text { Critérios de } \\
\text { desempenho }\end{array}$ & $\begin{array}{l}\text { Não foram identificados investimentos em aspectos sociais, porém nas questões } \\
\text { relacionadas ao aspectos econômico e ambiental verificaram-se práticas que seguem } \\
\text { exigências legais. }\end{array}$ \\
\hline
\end{tabular}

Fonte: Dados da pesquisa 

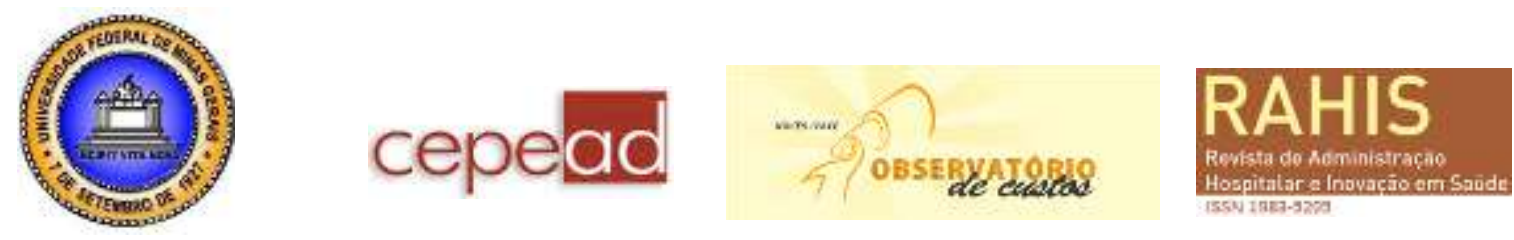

Diante do exposto, notou-se que a empresa em estudo não possui estratégias sustentáveis formalmente definidas, mas no geral, ela se torna sustentável pelo tipo de atividade que realiza, já que os aspectos sociais e ambientais são abordados como consequência.

Dessa forma, a organização busca a integração das dimensões social, ambiental e econômica em suas tomadas de decisões, pois no aspecto social realiza-se a proteção e contato contra risco infectante e biológico, já que impede que esses resíduos entrem em contato com a sociedade. No aspecto ambiental, a organização segue todas as legislações pertinentes e oferece tratamento e destinação final aos resíduos. Quanto ao aspecto econômico, o negócio é atrativo e a empresa não é filantrópica, portanto, deve gerar rentabilidade para os acionistas, ressaltando que o custo operacional é alto, devido as constantes renovações por meio de novas tecnologias e licenças. Contudo, verificou-se que a postura da empresa é reativa, pois seus programas de trato ambiental e social são vinculados ao orçamento e correspondem apenas a seguir as exigências legais, ou seja, a organização utiliza a estratégia da sustentabilidade como uma oportunidade de negócio.

\section{Considerações Finais}

A empresa objeto deste estudo possui a responsabilidade de fazer a coleta, transporte, tratamento e destino final adequado aos resíduos gerados pelos clientes (organizações da saúde), reduzindo os riscos ao meio ambiente e à população, tomando como seguimento a legislação vigente, que se encontra em constante mudança. Desse modo, teve-se por objetivos: (i) caracterizar as especificidades da coleta de resíduos de serviços de saúde; (ii) descrever a gestão dos resíduos na empresa; (iii) analisar as estratégias e ações sustentáveis realizadas na organização.

Verificou-se que o negócio da empresa é a minimização dos efeitos dos resíduos reduzindo seu impacto ambiental. Portanto, a utilização do sistema de gestão de resíduos é apenas uma forma de auxiliar os clientes, geradores de RSS, a segregar de forma rápida e fácil seus dejetos, garantindo a classificação dos resíduos, transportados e tratados pelos meios mais adequados disponíveis. Ainda, a empresa possui estreita colaboração com os órgãos reguladores ambientais e prestadores de novas tecnologias, garantindo assim as operações de eliminação na vanguarda da indústria.

Ressalta-se que existe uma percepção por parte dos gestores quanto aos objetivos econômicos, sociais e ambientais definidos pela organização. É possível verificar que a administração da empresa vem efetivamente pautando sua atuação com base em tais objetivos, pois esses aspectos encontram-se diretamente ligados às atividades da empresa. Ao atuar no ramo de resíduos especiais, a organização aproveita a oportunidade de negócio e contribui para a sustentabilidade do planeta, porém ainda pratica somente as ações sustentáveis previstas em lei.

Observa-se que os dados aqui relatados não devem ser considerados definitivos por se tratar de um estudo exploratório. Outras limitações desta pesquisa são próprias do estudo de caso como a não possibilidade de generalizações. Apesar disso, a questão analisada é de grande importância, abrindo diversas opções de análises empíricas, que poderão explorar outras indagações, a partir desse início, uma vez que, segundo Joshi (2013), a questão dos resíduos sólidos é extremamente preocupante e urgente. Ainda, recomendam-se novos estudos que busquem verificar a percepção de outras organizações sobre essa temática. 


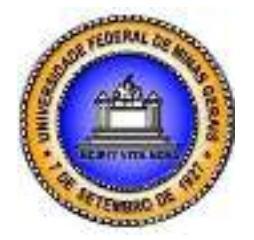

\section{Referências}

ABNT - ASSOCIAÇÃO BRASILEIRA DE NORMAS TÉCNICAS. NBR 12807. Rio de Janeiro: ABNT, 1993.

ALIGLERI, L.; ALIGLERI, L. A.; KRUGLIANSKAS, I. Gestão socioambiental: responsabilidade e sustentabilidade do negócio. São Paulo: Atlas, 2009.

ALMEIDA, F. O bom negócio da sustentabilidade. Rio de Janeiro: Nova Fronteira, 2002.

ALVES, M. L. A saúde ambiental e os resíduos de serviços de saúde nos três níveis de complexidade do sistema único de saúde - SUS. 2008. 96 fls. Dissertação (Mestrado em Desenvolvimento e Meio Ambiente) - Universidade Federal do Rio Grande do Norte, Natal, 2008.

AMARAL, S. P.; LA ROVERE, E. L. Oil e gas journal. V. 101, n.19, p.30, Tulsa: 2003.

ANDERSSON, L. M.; BATEMAN, T. S. Individual environmental initiative: Championing natural environmental issues in u.s. business organizations. The Academy of Management Journal, v. 43, n. 4, p. 548-570, 2000.

ASHLEY, P. A. Ética e responsabilidade social nos negócios. São Paulo: Saraiva, 2003.

BARBIERI, J. C.; CAJAZEIRA, J. E. R. Responsabilidade social empresarial e empresa sustentável: da teoria à prática. São Paulo: Saraiva, 2009.

BRASIL. Agência Nacional de Vigilância Sanitária. Manual de gerenciamento de resíduos de serviços de saúde. Ministério da Saúde. Brasília: Ministério da Saúde, 2006.

BRASIL. Conselho Nacional do Meio Ambiente e Recursos Naturais Renováveis (CONAMA). Resolução $\mathrm{n}^{\circ}, 358$, de 29 de abril de 2005. Dispõe sobre o tratamento e a disposição final dos resíduos dos serviços de saúde. Diário Oficial. Brasília: 2005.

BRASIL. Agência Nacional de Vigilância Sanitária. Resolução RDC no 306, de 7 de dezembro de 2004. Dispõe sobre o Regulamento Técnico para o gerenciamento de resíduos de serviços de saúde. Brasília: ANVISA, 2004.

BRASIL. Lei n. 12.305, de 2 de agosto de 2010. Política nacional de resíduos sólidos [recurso eletrônico]. 2. ed. 73 p. Série legislação, n. 81. Brasília: Câmara dos Deputados, Edições Câmara, 2012.

CARRAMENHA, M. M. L. Gerenciamento de resíduos sólidos em serviços de saúde: uma contribuição para a avaliação do desempenho ambiental. Dissertação (Mestrado em Engenharia Ambiental Urbana) - Escola Politécnica da Universidade Federal da Bahia, Salvador, 2005. 

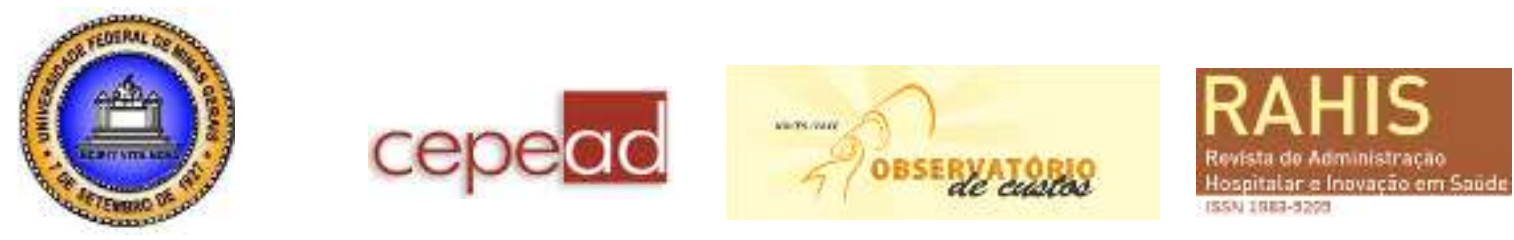

COELHO H. Manual de gerenciamento de resíduos sólidos de serviços de saúde. Rio de Janeiro: FIOCRUZ, 2001.

COELHO, N. M. G. P. Gerenciamento de resíduos de serviços de saúde: manejo dos resíduos potencialmente infectantes e perfurocortantes em unidades de internação da criança, adulto e pronto-socorro de hospitais públicos no Distrito Federal. 2007.154 fls. Dissertação (Mestrado em Ciências da Saúde) - Universidade de Brasília, Brasília, 2007.

COOPER, D. R; SCHINDLER, P. S. Métodos de pesquisa em administração. Porto Alegre: Bookman, 2011.

CORREAA, L. B.; LUNARDI, V. L.; DE CONTO, S. M. O processo de formação em saúde: o saber resíduos sólidos de serviços de saúde em vivências práticas. Revista Brasileira de Enfermagem, v. 60, n.1, p. 21-25, 2007.

DUTTON, J. E.; ASHFORD, S. J. Selling issues to top management. Academy of Management Review, n. 18, p. 397-428, 1993.

ELKINGTON, J. Canibais com garfo e faca. São Paulo: Makron, 2001.

GIL, A. C. Métodos e técnicas de pesquisa social. São Paulo: Atlas, 2010.

GLADWIN, T. N.; KENNELY, J. J.; KRAUSE, T. Shifting paradigms for sustainable development: implications for management theory and research. Academy of Management Review, New York, v. 20, n. 4, p. 874-907, 1995.

GLOBAL REPORTING INITIATIVE - GRI. 2013. Disponível em: <http://www.globalreporting.org> Acesso em 01/07/2013.

HAWKEN, P.; LOVINS, A.; LOVINS, H. Capitalismo natural: criando a próxima revolução industrial. São Paulo: Cultrix-Amana-Key, 2000.

HOPWOOD, B.; MELLOR, M.; O'BRIEN, G. Sustainable development: mapping different approaches. Sustainable Development, n. 13, p. 38-52, 2005.

KRAMAR, R.; HARIADI, M. F. Human resource management, performance and organizational sustainability: a new paradigm. Social Responsibility, Professional Ethics, and Management Proceedings of the 11th International Conference, Ankara, Turkey, 2427, November 2010.

JOSHI, H. D. Health care waste management practice in Nepal. Journal of Nepal Health Research Council, v. 11, n. 23, p. 102-108, 2013.

LINGANE, A.; OLSEN, S. Guidelines for social return on investment. California Management Review, v. 46, n. 3, p. 116-135, 2004.

MADERS, G. R.; CASTRO, H. S. de. A gestão dos resíduos dos serviços de saúde e os princípios do Direito Ambiental com ênfase na equidade intergeracional. Planeta Amazônia: Revista Internacional de Direito Ambiental e Políticas Públicas, n. 2, p. 11-20, 2010. 

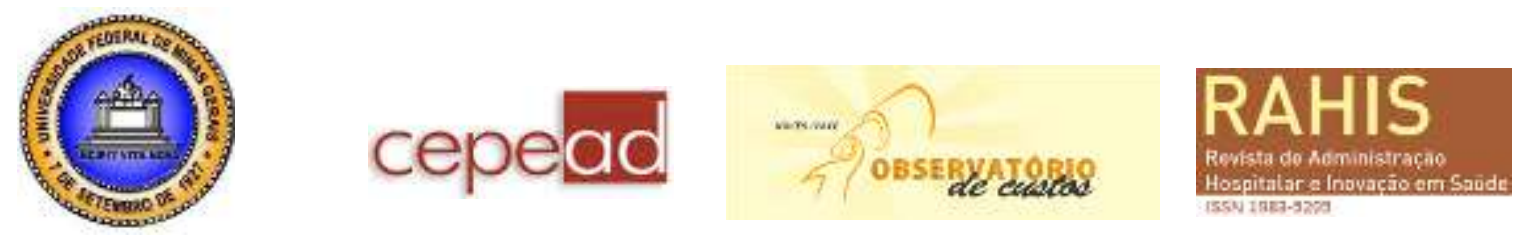

MARCONI, M. de A.; LAKATOS, E. M. Fundamentos de metodologia científica. São Paulo: Atlas, 2005.

MATTEN, D.; MOON, J. "Implicit" and "explicit" CSR: a conceptual framework for a comparative understanding of corporate social responsibility. Academy of Management Review, n. 33, p. 404-424, 2008.

MINAYO, M. C.; SANCHES, O. Quantitativo-qualitativo: oposição ou complementariedade? Caderno de Saúde Pública, v. 9, n. 3, p. 239-262, 1993.

MONTEIRO, J. H. P. Manual de gerenciamento Integrado de resíduos sólidos. Rio de Janeiro: IBAM, 2001.

MORESCHI, C. Resíduos de serviços de saúde: percepção de docentes, discentes e egressos da área da saúde de duas instituições comunitárias de ensino superior do RS. 2013. 146 fls. Dissertação (Mestrado em Ambiente e Desenvolvimento) - Centro Universitário UNIVATES, Lajeado, 2013.

PEREIRA, S.S.; LUCENA, L. L.; FERNANDES, A. Resíduos de serviço de saúde em um hospital de Campina Grande/PB: gestão e percepção ambiental. Revista Brasileira de Gestão e Desenvolvimento Regional, v. 6, n.3, p. 255-286, 2010.

PEREIRA, A. L.; BOECHAT, C. B.; TADEU, H. F. B.; SILVA, J. T. M.; CAMPOS, P. M. S. Logística reversa e sustentabilidade. São Paulo: Cengage Learning, 2012.

RODRIGUES, A. S. de L.; BASTOS, A. A.; MALAFAIA, G. Análise do gerenciamento dos resíduos sólidos de serviços de saúde na unidade básica de saúde do município de Urutaí, Goiás, Brasil. Enciclopédia Biosfera, v. 6, n. 11, 2010.

SCHILIZZI, S. Triple bottom line accounting: how serious is it? Connections. Online publication of Agribusiness Association of Australia, 2002.

SHRIVASTAVA, P. Ecocentric management for a risk society. Academy of Management Review, v. 20, n. 1, p. 118-137, 1995.

SHRIVASTAVA, P.; HART, S. Por uma Gestão Ambiental Total. HSM Management, São Paulo, n. 6, p. 92-96, 1998.

SILVA, V. A.; IOP, R. R.; SCHERER, F. L. Legitimidade institucional das estratégias em Gestão Ambiental: estudo de caso em uma organização de coleta de resíduos especiais. In: XII ENGEMA Encontro Internacional sobre Gestão Empresarial e Meio Ambiente, Anais..., São Paulo: Faculdade de Economia, Administração e Contabilidade da Universidade de São Paulo, 2010.

SILVA, V. A.; IOP, R. R. Estratégias e práticas ambientas na coleta de resíduos especiais. In: $1^{\circ}$ Fórum Internacional Ecoinovar, Anais..., Santa Maria: Universidade Federal de Santa Maria, 2012. v. 1. 
VERGARA, S. C. Projetos e relatórios de pesquisa em administração. São Paulo: Atlas, 2007.

YIN, R. K. Estudo de caso: planejamento e métodos. Porto Alegre: Bookman, 2010. 